\title{
Participation in work in early rheumatoid arthritis: a qualitative interview study interpreted in terms of the ICF
}

Anette Sverker, Ingela Thyberg, Gunnel Östlund, Eva Waltersson and Mikael Thyberg

\author{
Linköping University Post Print
}

Tweet

N.B.: When citing this work, cite the original article.

Original Publication:

Anette Sverker, Ingela Thyberg, Gunnel Östlund, Eva Waltersson and Mikael Thyberg, Participation in work in early rheumatoid arthritis: a qualitative interview study interpreted in terms of the ICF, 2014, Disability and rehabilitation, (36), 3, 242-249.

http://dx.doi.org/10.3109/09638288.2013.789086

Copyright: Informa Healthcare http://informahealthcare.com/

Postprint available at: Linköping University Electronic Press

http://urn.kb.se/resolve?urn=urn:nbn:se:liu:diva-102320 
Participation in work in early rheumatoid arthritis: A qualitative interview study interpreted in terms of the ICF

Annette Sverker ${ }^{1}$, Ingrid Thyberg ${ }^{2}$, Gunnel Östlund ${ }^{3}$, Eva Waltersson ${ }^{1}$, Mikael Thyberg ${ }^{4,5}$

${ }^{1}$ Rehabilitation Section, NSC, County Council of Östergötland, ${ }^{2}$ Rheumatology, Department of Clinical and Experimental Medicine, Faculty of Health Sciences, Linköping University, Department of Rheumatology in Östergötland, County Council of Östergötland, Linköping, Sweden; ${ }^{3}$ Department of Social and Welfare Studies, Linköping University;

${ }^{4}$ Rehabilitation Medicine, Department of Health and Society, and the ${ }^{5}$ Swedish Institute for Disability Research, Linköping University, Linköping, Sweden.

Corresponding author: Ingrid Thyberg

e-mail: ingrid.thyberg@lio.se 


\section{Abstract}

Purpose. To explore what work related dilemmas are experienced by patients with early rheumatoid arthritis (RA), according to their own descriptions, and to interpret this in terms of participation categories of the International Classification of Functioning, Disability and Health (ICF).

Method. In 48 patients with early RA, qualitative interviews were analyzed, followed by linking of concepts to the activity/participation component of the ICF and interpretation of general themes.

Results. Work related dilemmas represented different societal perspectives on work related to acquiring, keeping, and terminating a job, self-employment, part-time, full-time, and nonremunerative employment. Dilemmas also represented participation priorities in economic self-sufficiency, self-care such as health care, and avoiding social relationships and recreation in favour of work. Leisure time was influenced because efforts of working took energy and time of day-to-day procedures. Embedded actions in work related dilemmas were carrying out daily routine, mobility including using transportation, self-care, domestic life, and social interaction.

Conclusion. The general themes societal perspectives, participation priorities and embedded actions, with the included ICF categories that are described in detail according to the experiences of the patients, can support clinical reasoning and research on quantitative relations to disease activity, body functions, ability and contextual factors.

Keywords: ICF, participation, rheumatoid arthritis, work 


\section{Introduction}

Rheumatoid arthritis (RA) is a chronic inflammatory disorder that often results in restricted participation in work. Even early in the disease process this is common despite early pharmacological interventions with disease-modifying anti-rheumatic drugs (DMARD) [15]. Work disability in RA is dependent on many factors, such as disease activity, activity limitations and environmental demands [6-8]. Also, from qualitative approaches, it is known that patients with RA experience that participation in work is influenced by symptoms such as morning stiffness, fatigue and pain as well as environmental factors such as support from employers and colleagues [9]. However, in some contrast to the knowledge about RA disease mechanisms which has made pharmacological interventions effective, the work disabling mechanisms in early RA are not well described in relation to any comprehensive model of disability. Thus, apart from interventions targeting the disease process as such, reflected by e.g. the disease activity score 28 joint count (DAS-28), it is difficult for clinicians to know what aspects of work disability are crucial to target with multiprofessional rehabilitation measures in order to support participation in work. Work disability is an interdisciplinary issue with a need for several levels of analysis, but it is not yet clear how knowledge regarding e.g. medical and social aspects can be best integrated in order to support rehabilitation practices [10-16]. Within a health care perspective, disease activity, impairments, activity limitations and restricted participation in work have been studied, but results are difficult to interpret because of references to different models of disability, such as the disablement process model or the model of the International Classification of Functioning, Disability and Health (ICF), or the quite common use of different concepts and variables without reference to any comprehensive model [1-2,7,1722,]. In addition to individual aspects of functioning such as body functions and an individual's ability to perform certain activities, the ICF model includes participation which 
is the actual performance of activities in a social context. Regarding the ability of the individual, several assessment instruments have been developed and within a psychometric perspective it has been possible to make selections of items because many abilities correlate fairly well with each other [21,23-26]. However, it is more difficult to know how participation in work should be assessed in order to understand and prevent work disability; it is not clear what categories within the ICF activity/participation component that have to be considered when relating participation to e.g. disease activity, body function, ability and contextual factors [26-27]. Also, the ICF does not explain the nature of the relations between different aspects that are defined in terms of categories and domains [11].

The relative lack of knowledge with respect to the participation aspect is problematic in rehabilitation practices, both when analyzing the situation of individual patients and when designing clinical studies on the mechanisms of restricted participation in work, i.e. the modes of interaction between the mentioned components of the ICF model of disability. A necessary step in studying work disabling mechanisms is probably to analyze the qualitative content of the participation component as such. For this purpose, the value of experiencenear approaches is well recognized, but a need to relate findings to theory and interdisciplinary models of disability is also increasingly recognized in rehabilitation research $[9-12,20]$. The aim of this study was to explore what work related dilemmas are experienced by patients with early RA, according to their own descriptions, and to interpret this in terms of participation categories of the ICF.

\section{Methods}

\section{Design}

A qualitative methodology with semi-structured individual face-to-face interviews and condensation of transcribed data was used. This was followed by ICF linkage, description of work related dilemmas and inductive interpretation of general themes emerging from the 
data. This study is focused on participation in work, but data were collected regarding dilemmas of all kinds of everyday life activities with a possibility to analyze other aspects in a separate study.

The study was approved by the Research Ethics Committee of the Faculty of Health Sciences, Linkoping University (Approval No. M168-05 T84-09). Informed consent was given by the patients.

\section{Patients}

Patients for this study were recruited from the 522 patients who were included in the second cohort (TIRA-2) of the prospective multi-centre early arthritis project with the Swedish acronym TIRA [21] during 2006-2009. These patients fulfilled at least four of the seven 1987 American College of Rheumatology classification criteria (ACR-87) or had morning stiffness $\geq 60$ minutes and symmetrical arthritis in small joints or had positive Anti-CCP and $\geq 1$ peripheral joints with synovitis. Data for disease activity, disability and ongoing disease modifying anti rheumatic drugs (DMARD) were registered at inclusion and at 3, 6, 12 months after inclusion and thereafter annually. All patients were offered pharmacological treatment, physiotherapy, occupational therapy and social counselling at an individual schedule depending on individual needs during the study period. Disease activity was assessed according to the 28-joint count disease activity score (DAS28) and activity limitation was reported with the Swedish version of the Health Assessment Questionnaire (HAQ) [28].

In addition to the criteria of early RA for the TIRA-2 cohort, the specific inclusion criteria for this study were age 20-63 and having recently experienced the first 3 years after diagnosis. The inclusion started 2009 and the first 59 patients from the TIRA-2 cohort who fulfilled the specific criteria were invited to participate by a letter with information about the aim of the study, that their participation would be voluntary and that they could withdraw at any time without affecting interventions. Two weeks later, they were asked by telephone 
about participating. Of these 59 patients, 48 were included and 11, eight women and three men, did not want to participate due to "lack of time", "no dilemmas related to RA", or "lack of interest”.

Socio-demographic characteristics of the included 48 patients at the time for diagnosis are shown in table 1 . The purpose of table 1 is just to show the result of the sampling with respect to desirable variation regarding aspects that were a priori assumed to influence experiences, i.e. without any further intention to compare patients or sub-groups with each other. At the 3-year follow up, their median DAS28 was 2.4 with an inter quartile range of 0.63, 88\% had DMARD prescribed and their median HAQ score was 0.25 with an inter quartile range of $1.0 .76 \%$ of the women and $80 \%$ of the men were working. Details of employment status are shown in table 1.

\section{Data collection}

Each patient was interviewed by one of three interviewers: a social worker (AS or GÖ) or an occupational therapist (EW). The interviewers had experience from qualitative interviews and they were clinically experienced but not involved in the treatment. At the start of the study and until the interviews were completed they knew the general model of the ICF, but they were not familiar with the specific domains and categories of the classification system. A confidential place was chosen by the patients: at home, the workplace, at the hospital or university. The interviews were semi-structured with open-ended questions about everyday life dilemmas related to RA, using the critical incident technique (CIT) [29-32], without reference to any concepts or categories of the ICF. CIT means that problematic situations, called incidents or dilemmas, that have been experienced by the interviewee are explored by the interviewer. Each description of such an incident/dilemma that is acquired with CIT may be regarded as a unit for further analyses. The use of CIT means that there was a focus on human actions in real situations, in contrast to e.g. general feelings and beliefs, and a focus on recently experienced situations, in contrast to things that happened in the past or were expected to happen in the future. In some contrast to the original use of CIT (29), we adhere 
to recent usages that include the study of dilemmas that are not necessarily short incidents (30-31). This is indicated by the use of the term dilemma instead of the term incident. CIT also implies a consequent use of open-ended questions in order to permit the patients to respond in their own terms, minimizing the imposition of predetermined responses. Interviews started with questions such as: How is your everyday life? Please, describe a situation in your everyday life, preferably during the last week, when you were hindered by or reminded of your RA. Follow-up questions encouraged the patient to describe more about mentioned situations/dilemmas, consequences, and other situations they had experienced. The Swedish words that were used to ask about everyday life had a general meaning that covered work related situations as well as other everyday situations and follow-up questions were used with respect to all kinds of everyday life situations.

The interviews which lasted between 45 and 90 min were registered digitally and transcribed verbatim. The data collection period was between October 2009 and June 2010.

\section{Condensation of transcribed text}

The transcribed interview text of each interview was read by the interviewer several times to become familiar with the data, to obtain a sense of the whole and with an intention to avoid influence from preconceptions as far as possible. In the next step, descriptions including situations and actions of each dilemma were marked and abstracted from the text. In parallel with repeated re-readings of both the abstracted parts and the whole text, the condensed descriptions of each dilemma were then sorted into a tabular form, still using the words of the patients. The following three examples show how the resulting boxes of condensed information looked like, each representing a reported dilemma:

1. I am peeling potatoes at my workplace. Part-time employment. Work at a conference centre. Cleaning and kitchen. I have workmates in the kitchen who do other tasks. My main task when I work in the kitchen is to peel different root vegetables, otherwise I work with cleaning. I get pain in my thumb and my fingers. I stop peeling potatoes. My 
workmates tell me to sit down and take it easy. I take a pill, the pain disappears after 30 minutes. Then, I can work again.

2. I am at my workplace. Nurse. Full-time employment. A patient calls. I saw that he was in a hurry to get to the toilet. He is not very mobile and has to be lifted into a wheelchair. I do not fix this. I hurry away to find a workmate who can help me to get the patient to the toilet. My workmates accept that I can't do this, they think it's okay. My feeling is, isn't anybody irritated about this?

3. When I take the plates out from the dishwasher, at home, I pick 2 or 3 plates, you think you have a grip and then you lift but do not have that function in the hand, to grasp, but drop the things. Are not aware that it slips out of the hand. Have better function in the left, are more swollen in the right, often you can shift and lift a little more with the left. Think this should not be a problem but one has to accept it is like this.

After the ICF linkage of all dilemmas as described below, dilemmas such as the third example above, which were not linked to any work related category (domain 8 of the ICF activity/participation component), were sorted out for later analysis in a separate study. Results regarding the 98 dilemmas that were related to work, according to the ICF linkage, are reported in this paper. Out of the interviewed 48 patients, 26 women contributed with descriptions of 1-6 work related dilemmas each and 13 men contributed with descriptions of 1-6 work related dilemmas each. Thus, 9 patients did not report any work related dilemma.

\section{ICF linking}

After the condensation of transcribed text, one of the interviewers (EW) studied the ICF classification system and the ICF linking rules [11,33] with support from a specialist in rehabilitation medicine (MT) who was familiar with the ICF, domains, categories, definitions and linking rules. In the next step, these two authors interpreted each condensed description of a dilemma in terms of ICF activity/participation categories and codes, according to the updated ICF linking rules [33]. According to the linking rules, a dilemma 
could get one or several codes and the most precise codes that were possible depending on what concepts were included in the descriptions. In the ICF, the precision of a code is expressed in terms of 3 or 4 digit levels and the latter represents the most detailed code that is possible. There is also a 1 digit level coding possibility, just indicating one of the 9 domains of the activity/participation component. The authors first performed the coding independent from each other. The results were then compared, and diverging results were discussed until agreement was obtained: At a 3 digit level, the initially diverging results were related to whether one had paid enough attention to the ICF definitions regarding combinations of issues of domestic life with remunerative work; according to the definitions, so called household task codes may be combined with codes of remunerative work when performed as a part of the work, e.g. preparing meals, whereas other domestic life codes may not, such as caring for household objects and assisting others. At a 4 digit level, there were initially some diverging results and a discussion leading to consensus regarding what ICF aspects of fine hand use were explicit in the description provided by the patient.

Although new combinations of codes appeared (table 2), a criterion of saturation of data was that the last 10 of 98 work related dilemmas that were linked to the ICF did not result in any new codes.

\section{Description and thematic interpretation}

After the ICF linking procedure, the two authors who had made the linkage made a detailed description, integrating the types of dilemmas that were described by the patients with the corresponding terminology and codes of the ICF. This was followed by a further interpretation with respect to general themes emerging from the data. This interpretation was performed by alternating between so called open readings of descriptions and patterns of ICF linkages, and readings in order to confirm the interpretation [34]. Here, open readings may be said to represent a conscious attitudinal shift in order to minimize the influence from preconceptions, to look with a kind of naïve attitude before interpreting. During such 
readings, general patterns/themes may be perceived to emerge inductively from the more particular data. Such interpretations are then checked by repeated alternative readings in which one checks whether the perceived patterns actually exist in the data, if there are alternative or even opposite interpretations that are more reasonable given the data. The effort to interpret the whole material with such alternating modes of reading included the resulting patterns of ICF categories as well as the corresponding descriptions provided by the patients.

\section{Validation}

The general description and interpretation was then scrutinized against the interview data and approved by each of the interviewers independently. Also, it was scrutinized against the condensed descriptions of each dilemma and approved by an occupational therapist (IT) who had not been involved in the interviews or analysis of data.

\section{Terminology}

In this study, the term activity is used simply to denote different types of activities as such, corresponding to the whole ICF activity/participation list of things that people may do, and the term participation is used to denote the performance of such activities in a context, from simple actions such as lifting an object to complex actions such as work, according to option 4 of annex 3 of the ICF [11,26-27]. Consequently, the prefix p is used in front of the numerical codes to denote a participation aspect [11].

\section{Results}

\section{ICF linkages of dilemmas}

As explained in the methods section, each of the 98 work related dilemmas could be linked to one or several ICF participation codes/categories. As shown schematically in table 2, the 
linkage resulted in a number of different codes/categories and combinations of such

codes/categories. In the first two columns of the table, the kind of work related category and code, such as apprenticeship (p840), attributed to a dilemma is described. The next three columns describe additional participation categories and codes, such as preparing meals (p630), and lifting and carrying objects (p430), which were included in the descriptions of many dilemmas according to the linkage. For each kind of combination, codes with a higher number than other included codes are shown as included ICF codes in the first of these three columns. For dilemmas with more included codes, these are shown as additional included ICF codes in the second of these three columns. The ICF categories corresponding to included codes are described in the third of these three columns. The number of dilemmas in which a certain combination of codes/categories was found is given in column 6 of table 2, just to give a schematic overview of the ICF linkage results and without any intention of quantitative comparison. For the purpose of schematic overview, the linkages that resulted in ICF codes/categories at the more detailed 4 digit level as reported in the text of the results section are shortened to the corresponding 3 digit level in the table. Together with participation concepts in the text, the corresponding ICF codes are inserted within parentheses, at least when they first appear, in order to relate the detailed descriptions to table 2 and the participation component of the ICF.

\section{General themes}

The resulting work related descriptions together with the resulting ICF categories were interpreted to represent 3 general themes, emerging from these data: societal perspectives, participation priorities, and embedded actions. Some quotations are given in order to exemplify the general themes.

The general theme societal perspectives on work emerged from the complexity of different perspectives from which other people were experienced or expected to describe the patient's participation in work. Sometimes, there was a focus on the degree of employment or having 
sick-leave compensation (p8701) in relation to so called full-time employment (p8502) in the perspective of the social insurance agency: "I am worried about the rules of the social insurance, do not know if I can go on working, not sure if I am allowed to be on sick-leave, feel like a second class person, hoping for humane rules so one is allowed to be on sickleave..." Sometimes, there was a focus on productivity or the process of keeping (p8451), or leaving a job (p8452) in the perspective of the employer: "At the job, a high speed is necessary... I was crying because the work was so heavy but I told the chief about my RA, have an understanding chief...The chief did not know about my RA until last week, saw that I was limping...I told about the diagnosis, but I perform what I am expected to do...I function well...” Sometimes there was a focus on seeking a job (p8450), in the perspective of presumptive employers: “To apply for a job was difficult, first I was honest and wrote about RA but nobody answered...learnt to live with $R A$, not to write about RA in applications for a job...”

The general theme participation priorities emerged from descriptions exemplifying that it was difficult to talk about participation in remunerative work (p850) without paying attention to how this interacted with other aspects of social life, i.e. dilemmas of choosing between alternative issues of participation such as leisure activities (p920). The described situations were characterized by special features that were interpreted to have appeared together with the disease: "Leisure activities have to be postponed because of tiredness after work ...they say that you have to accept that it is so to say the picture of the disease, that you are tired...there is no energy left, it is empty."

The general theme embedded actions emerged from the performance of other categories described as parts of a work related dilemma: “...trained for a job (p840) at a day-centre...I did cooking (p630) at the job...had difficulties to lift (p4300) pots and pans...” 
The described dilemmas represented societal perspectives on participation in work in which quite different aspects, such as stages of work and the amount or form of work were paid attention to. In terms of the ICF, the descriptions represented acquiring, keeping, as well as terminating a job. With respect to acquiring a job, there were descriptions related to applying for a job, such as fear about being offered a job and then being unable to manage the work, thoughts about what degree of physically demanding jobs one should apply for with concern for the RA, and also whether or not to tell about the RA at an interview with a presumptive employer. With respect to keeping a job, there were also descriptions related to whether to tell about the RA at a new job. Another kind of description was related to whether or not the work responsibilities could be sufficiently changed and adapted to the individual needs of the patient, and the different interests and perspectives of other involved parts such as the employer and the social insurance agency. With regard to the described attitudes of the employer, the examples ranged from expectations to go on working as hard as before the diagnosis of RA to discussions about reasonable limitations and adaptations, and explicit recommendations from the employer to do the easy parts of the work. Also, descriptions of keeping a job were related to being confronted with getting less responsibilities or a lower position, e.g. when returning from a period of sick-leave. With respect to terminating a job, descriptions related to decisions about leaving a job earlier than the ordinary time for retirement. Such descriptions also related to loss of social relationships with workmates. Terminating a job was related to one’s own needs being confronted with diverging expectations from the employer and the social insurance agency. E.g. the social insurance agency demanded that the employer should either arrange a more adapted job or terminate the employment. Also, the descriptions represented remunerative employment in terms of self-employment (p8500), part-time employment (p8501), full-time employment (p8502) as well as non-remunerative employment (p855). With respect to self-employment, there were difficult decisions about selling parts of e.g. farming or forestry property in order to manage the maintenance of the rest. With respect to part-time employment, descriptions related to 
lack of energy or mobility causing problematic work situations in spite of arrangements with different degrees of part-time employment and/or part time sick-leave on the basis of the RA diagnosis. With respect to full-time employment, descriptions related to not having reduced the working time yet, implying lack of energy for anything else than the work, problems to concentrate on the work, and a need to change work responsibilities in order to go on with full-time employment. There were also descriptions of reluctance to show any symptoms of RA at the workplace. Non-remunerative employment was exemplified with mobility limitations causing difficulties to continue participation in a voluntary organization.

\section{Participation priorities}

The described dilemmas also represented participation priorities in terms of economic selfsufficiency (p870) and in terms of other domains of participation which were described to have become influenced by the RA because the efforts to go on working took most of the energy and time of the day-to-day procedures (Table 2). Patients had difficulties to talk about participation in work without paying attention to how this interacted with other aspects of social life. There were dilemmas of choosing between working and keeping social relationships with friends or colleagues. The issues of economic self-sufficiency included problematically low income when being on sick-leave, the risk of losing the economic support from the social security agency, and also the risk of losing the job. Work related descriptions that involved other domains of participation represented self-care (p5), social relationships (p7), as well as recreation and leisure (p920). With respect to self-care, the issue was about problematic timing of visits to health care professionals, i.e. looking after one's health (p570), if one was reluctant to tell about the RA at the workplace. With respect to social relationships, one type of priority issue was related to choosing between participating in evening activities of the staff of one’s workplace (p740) and participating in the ordinary work at the following day (p850), because the RA made the combination of these activities too demanding in terms of energy and fatigue (p230). Another type of 
priority issue involving social relationships was that fatigue made it necessary to go to rest and sleep when coming home after work, which was described as problematic with respect to intimate relationships with partners (p770). There was also the issue of having to give up recreation and leisure (p920) because one had to rest and sleep after work. The requirements in terms of energy and timing were experienced to make it difficult to prioritize anything else than work and the most basic contact with the family when coming home after work.

\section{Embedded actions}

Work related dilemmas included carrying out daily routine, mobility, using transportation, self-care, and social interaction in work (Table 2). There were descriptions concerning carrying out daily routines and managing one’s activity level in terms of energy and timing (p2303). The problem of handling fatigue was related to work as such and also to the described issue of prioritizing between work and other domains of participation. Several descriptions included a number of mobility (p4) in work issues. This was related to the basic body position, i.e. changing basic body position, such as into or out of sitting (p4103), and squatting (p4101), and maintaining a body position, such as standing (p4154). Also, descriptions included issues related to the upper extremities, i.e. carrying, moving and handling objects, such as lifting (p4300) and carrying in the hands (p4301), fine hand use, such as grasping (p4401) and manipulating (p4402), and also hand and arm use, such as reaching (p4452), and turning or twisting the hands or arms (p4453). In addition, descriptions included issues related to the lower extremities, i.e. walking and moving, such as short (p4500) or long (p4501) distances, and walking on uneven surfaces (p4502), moving around, such as crawling (p4550), climbing (p4551), running (p4552), and jumping (p4553), and also dilemmas related to the ICF category of moving around in different locations (p460). Dilemmas also included using transportation in work, such as driving human powered transportation (p4750) and driving motorized vehicles (p4751). This in its turn included other embedded actions, such as getting into and out of a seated position (p4103). 
In self-care in work, one type of description included problems to choose clothing (p5404) because the RA made it difficult to use the appropriate footwear at the workplace. Also, descriptions included managing diet and fitness (p5701), exemplified by difficulties to walk the distance to the workplace in order to get some daily physical exercise. Thus, this issue in its turn included actions in terms of mobility, such as walking (p450). Domestic life in work included preparing meals (p630) and doing housework (p640), such as peeling potatoes and cleaning an apartment. Whereas the ICF definitions corresponding to some descriptions of domestic tasks in work were found to exclude remunerative work (p650-660), the mentioned categories were not excluded. In their turn, such household actions included different mobility dilemmas. Social interaction in work was an embedded action that was related to the ICF concept of making and responding to bodily contact in a contextually appropriate manner (p7105), such as shaking hands.

\section{Discussion}

The research question of this study was limited to the analysis of problematic aspects of the work related participation component as such [11], assuming that this is a necessary step in using the ICF model to relate participation to other components. The well defined study group representing patients with early RA and the medication strategy of today, a majority still in work, socio-demographic variation and several interviewers using open-ended questions may be regarded as strengths of the study [11,29,34]. The ICF linkage supports interdisciplinary modelling of the mechanisms of work disability, which is probably a crucial step in future research to guide rehabilitation practices $[5,10,13,16,33]$. The use of the activity/participation component as a whole pays attention to social models of disability that do not recognize a decontextualized subcomponent of activity [11-12,14,26,35]. The aim was to explore what work related dilemmas are experienced by patients with early RA; there was no aim to compare the patients with each other and the results do not answer questions 
about how commonly the described aspects appear in early RA populations. First, there was a need to know the qualitative spectrum of such dilemmas as described by the patients themselves [34]. Then, there was a need to interpret these data in a way that would be useful to the further development of rehabilitation practices [36]. Of course, an alternative to the ICF linkage [33] could have been to interpret themes that seemed to emerge from the data without any influence from rehabilitation theory. However, the chosen approach may increase the usefulness of the results because it links the findings to an interdisciplinary and international rehabilitation terminology [11]. In the results section, the qualitative spectrum of dilemmas is described in detail using the corresponding ICF terms and codes. To practitioners, it is useful to be familiar with the described spectrum of work related dilemmas that may be experienced by a patient with early RA. The detailed descriptions constitute a quite heterogenous body of information and the ICF does not explain the nature of the relations between different aspects $(11,26-27)$. Thus, during the final step of the analysis, there was an attempt to make a data based interpretation of the resulting descriptions, including the resulting ICF categories. Although data based, such an interpretation is assumed to be influenced by e.g. the professional background of the researcher, which is not necessarily a disadvantage in applied rehabilitation research [16,34,37]. The general themes of societal perspectives, participation priorities and embedded actions seemed to emerge. These concepts are more abstract than the detailed descriptions and may be useful to practitioners in order to organize knowledge and clinical reasoning.

Societal perspectives on participation in work highlight that practitioners may face quite different ways to analyze participation; the perspective of the patient may not be the same as the perspectives of persons representing other interests. For example, a social insurance agent may focus on medico-legal conceptions of work ability while an employer is concerned about productivity and an employment agent may focus on employability on a competitive labour market while the patient is concerned about attending work, economic self-sufficiency and keeping a job despite periods of sick-leave [1,35,38]. If such 
perspectives are made explicit it is easier to help patients to interact optimally. In rehabilitation practices, the concept of participation priorities is useful because it highlights the difference between an individual's ability and the actual performance of activities, which may be affected by a number of contextual factors $[14,26]$. Although primarily focusing on ability, research using the valued life activities instrument has addressed the relative importance of different activities [39]. Also, researchers relating to the HAQ [23] or the ICF model [26] have discussed whether the perceived importance of activities should be included in assessments. In RA patients, declines in the ability to engage in recreational activities and social interactions are related to the onset of depressive symptoms [39], which may in its turn influence participation in work. Measures of work ability will probably correlate positively with measures of the ability to perform the described issues of self-care, social relationships, and recreation and leisure [25-26], but the results regarding participation priorities suggest that the performance of work in early RA will not necessarily show high positive correlations with the actual performance of other valued domains of participation. Embedded actions in terms of carrying out daily routine, mobility, using transportation, selfcare, and social interaction in work are important for the choice of interventions in patients at risk for restricted participation in work indicated by e.g. sick leave or a high HAQ score $[3,21,25]$. Regarding each kind of embedded action, the general ability to participate in work may be facilitated by interventions supporting the ability of the individual as well as interventions on environmental factors [36]. In clinical reasoning and even with respect to medico-legal questions that rehabilitation practitioners may have to deal with, limitations or restrictions regarding the described embedded activity/participation categories may be conceived as causes of work disability $[17,40]$. However, the issue of causation is problematic with respect to partly overlapping definitions, temporal relations and levels of analysis [10-13,17,27,40-43]. For example, the disablement process model [17], which is sometimes referred to, is somewhat similar to the predecessor of the ICF model [40] with respect to a priori assumptions about causal directions included in the definitions of the 
components of disability. This feature has been criticized by e.g. disabled people and researchers emphasizing social causes of disability [10,12,42-44]. The ICF model, recognizes the possibility to analyze corresponding body functions, activity/participation aspects and contextual factors in parallel during the disease process and to leave questions about causal relations open for empirical studies [10-11,20,44]. The described embedded actions would be relevant to address in such research on work in early RA. In conclusion, the general themes societal perspectives, participation priorities and embedded actions, and the included ICF categories that are described in detail according to the experiences of the patients, can support clinical reasoning. Also, it can be used as a basis for research on quantitative relations to disease activity, body functions, ability and contextual factors.

\section{Declaration of interest}

The authors report no conflict of interest. The study was financially supported by the County Council of Östergötland Research Foundations, Medical Research Council of South-East Sweden (FORSS), Norrbacka-Eugenia Foundation and the Swedish Rheumatism Association.

\section{Acknowledgements}

Many thanks to patients for participating and research partner Birgitta Stenström for valuable comments. 


\section{References}

1. Burton W, Morrison A, Maclean R, Ruderman E. Systematic review of studies of productivity loss due to rheumatoid arthritis. Occupational Medicine 2006;56:18-27.

2. Geuskens GA, Burdorf A, Hazes JMW. Consequences of rheumatoid arthritis for performance of social roles: A Literature Review. J Rheumatol 2007;34:1248-1260.

3. Björk M, Thyberg I, Rikner K, Balogh I, Gerdle B. Sick leave before and after diagnosis of rheumatoid arthritis: a report from the Swedish TIRA project. J Rheumatol 2009;36:1170-1179.

4. Neovius M, Simard JF, Klareskog L, Askling J, ARTIS study group. Sick leave and disability pension before and after initiation of antirheumatic therapies in clinical practice. Ann Rheum Dis 2011;70:1407-1414.

5. Short P, Jones AC, Walker D, Kavanaugh A, Moots RJ. Working at arthritis. Rheumatology 2012;51:201-203.

6. Young A, Dixey J, Kulinskaya E, Cox N, Davies P, Devlin J, Emery P, Gough A, James D, Prouse P, Wiliams P, Winfield J. Which patients stop working because of rheumatoid arthritis? Results of five years follow up in 732 patients from the early RA Study (ERAS). Ann Rheum Dis 2002;61:335-340.

7. Backman C. Employment and work disability in rheumatoid arthritis. Curr Opin Rheumatol 2004;16:148-152.

8. Yelin E. Work disability in rheumatic disease. Curr Opin Rheumatol 2007;19:91-96.

9. Van der Meer M, Hoving JL, Vermeulen MIM, Herenius MMJ, Tak PP, Sluiter JK, Frings-Dresen MHW. Experiences and needs for work participation in employees with rheumatoid arthritis treated with anti-tumor necrosis factor therapy. Disabil Rehabil 2011;33:2587-2595. 
10. Bickenbach JE, Chatterji S, Badley EM, Ustün TB. Models of disablement, universalism and the international classification of impairments, disabilities and handicaps. Soc Sci Med 1999;48:1173-1187.

11. World Health Organization (2001) ICF: International classification of functioning, disability and health. Geneva: WHO; 2001.

12. Gustavsson A. The role of theory in disability research - springboard or straitjacket? Scand J Disabil Res 2004;6:55-70.

13. Bhaskar R, Danermark B. Metatheory, interdisciplinarity and disability research: a critical realist perspective. Scand J Disabil Res 2006;8:278-297.

14. Nordenfelt L. On health, ability and activity: Comments on some basic notions in the ICF. Disabil Rehabil 2006;28:1461-1465.

15. Coenen M, Cieza A, Stamm TA, Amann E, Kollerits B, Stucki G. Validation of the international classification of functioning, disability and health (ICF) Core Set for rheumatoid arthritis from the patient perspective using focus groups. Arthritis Res Ther 2006:8;R84.

16. Stucki G, Grimby G. Organizing rehabilitation research into distinct scientific fields. Part I: developing a comprehensive structure from cell to society. J Rehabil Med 2007;39:293-298.

17. Verbrugge LM, Jette AM. The disablement process. Soc Sci Med 1994;38: 1-14.

18. Allaire S, Keysor JJ. Development of a structured interview tool to help patients identify and solve rheumatic condition-related work barriers. Arthritis Rheum 2009;61:998995.

19. Kaptein SA, Gignac MAM, Badley EM. Differences in the workforce experiences of women and men with arthritis disability: a population health perspective. Arthritis Rheum 2009;605-613. 
20.

Cieza A, Bostan C, Oberhauser C, Bickenbach JE. Explaining functioning outcomes across musculoskeletal conditions: a multilevel modelling approach. Disabil Rehabil 2010;32:S85-S93.

21. Thyberg I, Dahlström Ö, Björk M, Arvidsson P, Thyberg M. HAQ as clinical indicator of persistent disabilities: The Swedish TIRA cohort 8 years after diagnosis of RA. Clin Rheumatol 2012;31:775-783.

22. Verstappen SM, Fautrel B, Dadoun S, Symmons DP, Boonen A. Methodological issues when measuring paid productivity loss in patients with arthritis using biologic therapies: an overview of the literature. Rheumatology (Oxford). 2012;51:216-29.

23. Hewlett S, Smith AP, Kirwan JR. Values for function in rheumatoid arthritis: patients, professionals, and public. Ann Rheum Dis 2001;60:928-933.

24. Garin O, Ayuso-Mateos JL, Almansa J, Nieto M, Chatterji S, Vilagut G, Alonso J, Cieza A, Svetskova O, Burger H, Racca V, Francescutti C, Vieta E, Kostanjsek N, Raggi A, Leonardi M, Ferrer M; MHADIE consortium. Validation of the "world health organization disability assessment schedule, WHODAS-2" in patients with chronic diseases. Health Qual Life Outcomes 2010;8:51.

25. Katz PP, Radvanski DC, Allen D, Buyske S, Schiff S, Nadkarni A, Rosenblatt L, Maclean R, Hassett AL. Development and validation of a short form of the valued life activities disability questionnaire for rheumatoid arthritis. Arthritis Care Res 2011;63:16641671.

26. Arvidsson P, Granlund M, Thyberg I, Thyberg M. International classification of functioning, disability and health categories explored for self-rated participation in Swedish adolescents and adults with a mild intellectual disability. J Rehabil Med 2012;44:562-569.

27. Badley EM. Enhancing the conceptual clarity of the activity and participation components of the international classification of functioning, disability, and health. Soc Sci Med 2008;66:2335-2345. 
28. Ekdahl C, Eberhardt K, Andersson SI, Svensson B. Assessing disability in patients with rheumatoid arthritis. Use of a Swedish version of the Stanford health assessment questionnaire. Scand J Rheumatol 1998;17:263-271.

29. Flanagan C. The critical incident technique. Psychol Bull 1954;51:327-358.

30. Sverker A, Hensing G, Hallert C. 'Controlled by food' - lived experiences of coeliac disease. J Hum Nutr Dietet 2005;18:171-180.

31. Hensing GKE, Sverker AM, Leijon GS. Experienced dilemmas of everyday life in chronic neuropathic pain patients: results from a critical incident study. Scand J Caring Sci 2007;21:147-154.

32. Schluter J, Seaton P, Chaboyer W. Critical incident technique: a user's guide for nurse researchers. J Adv Nurs 2007;61:107-114.

33. Cieza A, Geyh S, Chatterji S, Kostanjsek N, Ustun B, Stucki G. ICF linking rules: an update based on lessons learned. J Rehabil Med 2005;37:212-218.

34. Patton MQ. Qualitative research and evaluation methods. London: Sage; 2002.

35. Nordenfelt L. The concept of work ability. Brussels: PIE Peter Lang; 2008.

36. Stucki G, Cieza A, Melvin J. The international classification of functioning, disability and health: a unifying model for the conceptual description of the rehabilitation strategy. J Rehabil Med 2007;39: 279-285.

37. Johnsen V, Skattebu E, Aamot-Andersen A, Thyberg M. Problematic aspects of faecal incontinence according to the experiences of adults with spina bifida. J Rehabil Med 2009;41:506-511.

38. Hubertsson J, Peterson IF, Arvidsson B, Thorstensson CA. Sickness absence in musculoskeletal disorders - patients’ experiences of interactions with the social insurance agency and health care. A qualitative study. BMC Public Health 2011;11:107-115.

39. Katz PP, Yelin EH. Activity loss and the onset of depressive symptoms. Do some activities matter more than others? Arthritis Rheum 2001;44:1194-1202. 
40. World Health Organization. The international classification of impairments, disabilities and handicaps (ICIDH). Geneva: WHO; 1980.

41. Johnston M, Pollard B. Consequences of disease: testing the WHO international classification of impairments, disabilities and handicaps (ICIDH) model. Soc Sci Med 2001;53:1261-1273.

42. Nordenfelt L. On disabilities and their classification: a study in the theory of action inspired by the international classification of impairments, disabilities and handicaps (ICIDH). Linköping: Linköping University, Department of Health and Society; 1983.

43. Nordenfelt L. Action theory, disability and ICF. Disabil Rehabil 2003;25:1075-1079.

44. Thyberg M, Nelson MC, Thyberg I. A definition of disability emphasizing the interaction between individual and social aspects that existed among Scandinavian precursors of rehabilitation medicine as early as 1912. J Rehabil Med 2010;42:182-183. 
Table 1

Socio-demographic characteristics of the 48 patients included in the study.

Characteristics

Women

Men

$\mathrm{N}=34$

$\mathrm{N}=14$

$(71 \%)$

$(29 \%)$

\section{Age (years)}

$20-45$

8

1

46-55

8

3

$56-60$

11

7

61-63

7

3

\section{Education}

Elementary and occupational school

Upper secondary 2-years

Upper secondary 3-years

University

\section{Employment status}

Full-time work

Part-time work

Unemployed or sick-listed

Temporary disability pension/

Early retirement benefit 


\section{Table 2}

Work related ICF participation codes/categories resulting from linking of the condensed descriptions of dilemmas. Descriptions of a dilemma that included one more (column 3) or several (column 3 and 4) codes/categories resulted in combinations that are described in column 3-5. In column 5, the categories in bold refer to the codes of column 3 . The number of dilemmas in which a certain combination of codes was found is given in column 6 .

\begin{tabular}{|c|c|c|c|c|c|}
\hline $\begin{array}{l}\text { ICF } \\
\text { code }\end{array}$ & Category & $\begin{array}{l}\text { Included } \\
\text { ICF codes }\end{array}$ & $\begin{array}{l}\text { Additional } \\
\text { included } \\
\text { ICF codes }\end{array}$ & $\begin{array}{l}\text { Categories corresponding to } \\
\text { included codes }\end{array}$ & $\begin{array}{l}\text { Number } \\
\text { of } \\
\text { dilemmas }\end{array}$ \\
\hline p840 & $\begin{array}{l}\text { Apprenticeship } \\
\text { (work } \\
\text { preparation) }\end{array}$ & p630 & $\begin{array}{l}\mathrm{p} 430 \\
\mathrm{p} 445\end{array}$ & $\begin{array}{l}\text { Preparing meals } \\
\text { Lifting and carrying objects } \\
\text { Hand and arm use }\end{array}$ & 1 \\
\hline \multirow[t]{5}{*}{ p845 } & \multirow{5}{*}{$\begin{array}{l}\text { Acquiring, } \\
\text { keeping and } \\
\text { terminating a } \\
\text { job }\end{array}$} & \multicolumn{3}{|c|}{ No included ICF codes } & 16 \\
\hline & & p230 & & Carrying out daily routine & 1 \\
\hline & & p430 & & Lifting and carrying objects & 1 \\
\hline & & p750 & & Informal social relationships & 1 \\
\hline & & p870 & & Economic self-sufficiency & 1 \\
\hline \multirow[t]{4}{*}{ p850 } & \multirow{4}{*}{$\begin{array}{l}\text { Renumerative } \\
\text { employment }\end{array}$} & \multicolumn{3}{|c|}{ No included ICF codes } & 6 \\
\hline & & p160 & p230 & $\begin{array}{l}\text { Focusing attention } \\
\text { Carrying out daily routine }\end{array}$ & 2 \\
\hline & & p230 & & Carrying out daily routine & 10 \\
\hline & & p240 & & Handling stress and other & 1 \\
\hline
\end{tabular}




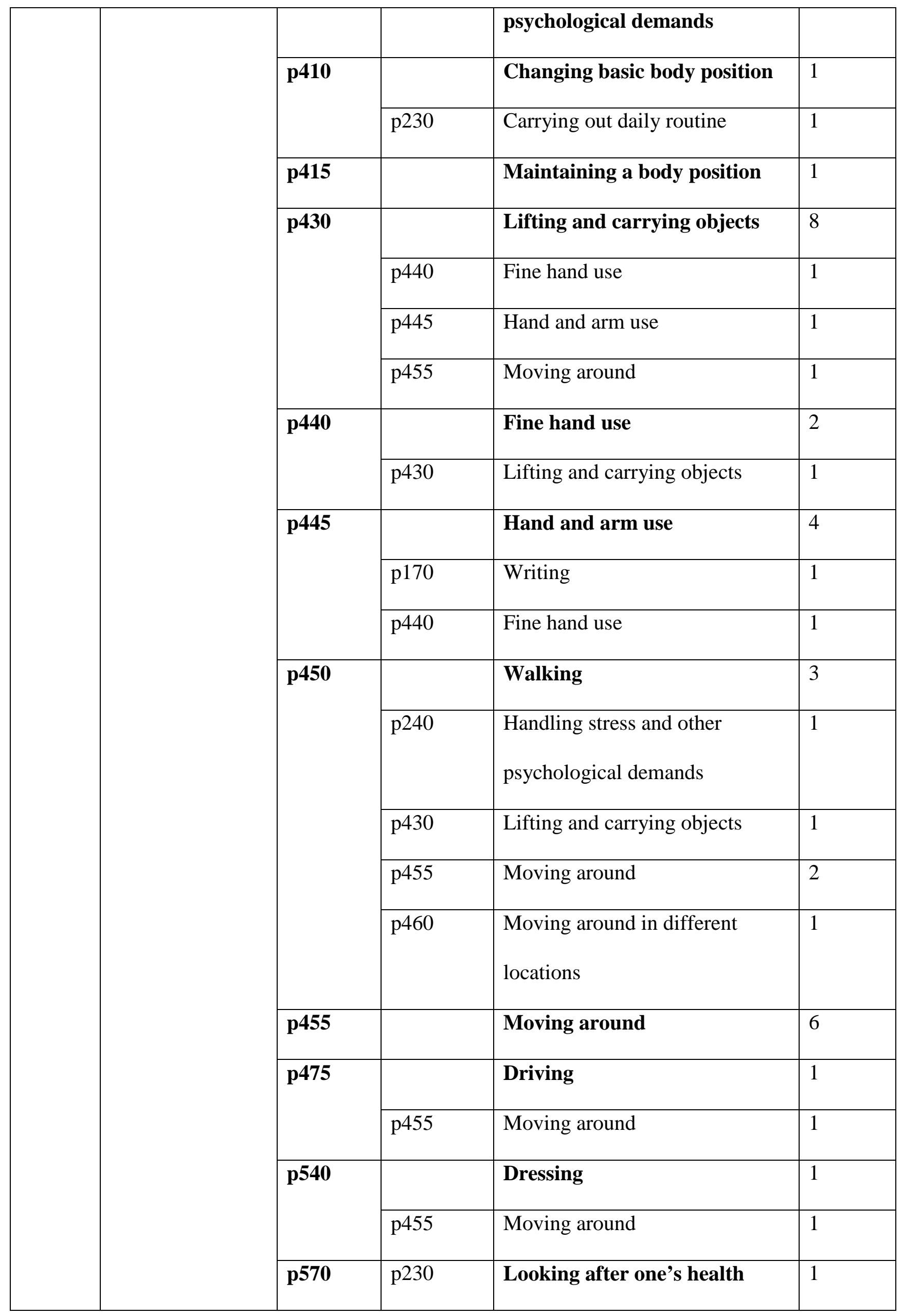




\begin{tabular}{|c|c|c|c|c|c|}
\hline & & & $\mathrm{p} 450$ & Walking & 1 \\
\hline & & p630 & p445 & $\begin{array}{l}\text { Preparing meals } \\
\text { Hand and arm use }\end{array}$ & 2 \\
\hline & & p640 & p230 & $\begin{array}{l}\text { Doing housework } \\
\text { Carrying out daily routine }\end{array}$ & 1 \\
\hline & & $\mathbf{p} 7$ & p450 & $\begin{array}{l}\text { Interpersonal interactions and } \\
\text { relationships } \\
\text { Walking }\end{array}$ & 1 \\
\hline & & p710 & & $\begin{array}{l}\text { Basic interpersonal } \\
\text { interactions }\end{array}$ & 1 \\
\hline & & p740 & p230 & $\begin{array}{l}\text { Formal relationships } \\
\text { Carrying out daily routine }\end{array}$ & 1 \\
\hline & & p770 & p230 & $\begin{array}{l}\text { Intimate relationships } \\
\text { Carrying out daily routine }\end{array}$ & 1 \\
\hline & & p920 & p230 & $\begin{array}{l}\text { Recreation and leisure } \\
\text { Carrying out daily routine }\end{array}$ & 1 \\
\hline p855 & $\begin{array}{l}\text { Non- } \\
\text { renumerativ } \\
\text { employment }\end{array}$ & p430 & & Lifting and carrying objects & 1 \\
\hline $\mathbf{p 8 7 0}$ & Economic sel- & No in & d ICF & & 1 \\
\hline & sufficiency & p240 & & $\begin{array}{l}\text { Handling stress and other } \\
\text { psychological demands }\end{array}$ & 1 \\
\hline & & p750 & & Informal social relationships & 1 \\
\hline & & p850 & & Remunerative employment & 3 \\
\hline Total & eer of dilen & & & & 98 \\
\hline
\end{tabular}

